\title{
AN OVERVIEW OF THE ALTERATION OF ORTHODONTIC TREATMENT RESULTS WITH A REMOVABLE ORTHODONTIC APPLIANCE USING LITTLE'S IRREGULARITY INDEX: PRELIMINARY STUDY OF THE DENTAL HOSPITAL FACULTY OF DENTISTRY, UNIVERSITAS INDONESIA, INTEGRATION CLINIC PATIENTS
}

\author{
Beattie Rahayu, Nada Ismah, Widya Kusumadewy, Krisnawati \\ Department of Orthodontics, Faculty of Dentistry, Universitas Indonesia, Jakarta, Indonesia
}

\begin{abstract}
INTRODUCTION: The complexity of malocclusions, such as anterior dental irregularity, is important in determining the outcome of treatment with a removable orthodontic appliance. Little's Irregularity Index is used to assess alterations of anterior teeth.

MATERial AND MEthods: This was a descriptive study done on 47 patients' dental casts before and after treatment using a removable orthodontic appliance, between 2013 and 2017. Measurements were made using Little's Irregularity Index.

RESULTS: Patients who presented most often for removable orthodontic appliance treatment had minimal and moderate anterior dental irregularity. After treatment completion, the condition of the patients' anterior teeth was altered to having either no or minimal irregularities, and no further patients had severe irregularities.

Conclusions: The condition of patients' maxillary and mandibular anterior teeth improved after undergoing removable orthodontic appliance treatment provided by dental students at our dental hospital between 2013 and 2017. Thus, the treatment given can be considered appropriate and in accordance with removable orthodontic appliance indications and functioning.
\end{abstract}

KEY wORDS: removable orthodontic appliance, Little's Irregularity Index, treatment result.

\section{INTRODUCTION}

Anterior dental irregularity is the most common malocclusion characteristic [1]. Based on Indonesian National Health Research in 2013, the prevalence of dental irregularities in Indonesia's overall population was $14.3 \%$ [2]. Dental irregularity refers to an overlapped condition of teeth that are therefore beyond the proper dental arch [3]. The irregularity of teeth, especially the anterior teeth, becomes aesthetically unpleasing, for example when a person is smiling [4]. This creates discomfort and disrupts

JOURNAL OF STOMATOLOGY CZASOPISMO STOMATOLOGICZNE

AdDRESS FOR CORRESPONDENCE: Nada Ismah, Department of Orthodontics, Faculty of Dentistry, Universitas Indonesia, Jalan Salemba Raya No.4, Jakarta Pusat, Jakarta 10430, Indonesia, e-mail: nada.ismah@ui.ac.id or nadalukman@yahoo.com 
the overall appearance, which leads to patients seeking orthodontic treatment.

Two types of orthodontic appliances are used for treatment (removable and fixed types) [1], including active (mechanical appliances and functional appliances) and passive (retainers and space maintainers) removable orthodontic appliances [1]. An active removable orthodontic appliance is indicated for simple malocclusions without any skeletal abnormalities such as: mild crowding and multiple diastema, non-extraction and mixed dentition cases, limited tooth movement like tipping, and arch expansions $[1,3]$ The design of this appliance consists of a clasp, a spring, and an acrylic plate that can be removed by the patient [5]. Patient compliance for routine use of the appliance and periodic control becomes an important part of achieving the desired orthodontic treatment outcome [3].

In their study, Skidmore et al. [6] suggested that several factors affect treatment outcomes, including the duration of use, complexity of malocclusion, treatment methods, patient cooperativeness, and sociodemographic characteristics. The complexity of malocclusions is a main factor in successful orthodontic treatment [6]. Success is evaluated from treatment outcomes and becomes important as the demand for orthodontic treatment rises, and as a form of improved quality of treatment.

A variety of simple indexes are used to assess the complexity of malocclusions. In 1975 Little introduced the irregularity index to assess the complexity of malocclusions [7]. This index was used to assess alteration of the anterior arrangement of the teeth of each jaw by using digital callipers to measure the distance from the contact point of each incisor to the adjacent tooth contact point [7-10]. Measurement with Little's Irregularity Index results in five categories of irregularities: category $1-$ no irregularity/perfect alignment; category 2 - minimum; category 3 - moderate; category 4 - severe; and category 5 - very severe irregularity [7-10].

Orthodontic treatment using a removable appliance was performed by dental students at the Dental Hospital of the Faculty of Dentistry, Universitas Indonesia integration clinic. Each case was indicative for the removable orthodontic appliance and was approved by the clinical supervisor. No previous studies were conducted to examine the results of treatment with a removable orthodontic appliance using Little's Irregularity Index at the Dental Hospital of the Faculty of Dentistry, Universitas Indonesia integration clinic.

\section{MATERIAL AND METHODS}

This observational descriptive cross-sectional study was conducted on patients recruited from the Orthodontic Integration Clinic of the Dental Hospital Faculty of Dentistry, Univeritas Indonesia Salemba, Central Jakarta, Indonesia between 2013 and 2017. Inclusion cri- teria were: age 12-24 years, patients currently in the permanent dental period, class I skeletal case, and a dental cast obtained before and after treatment, including those who did not finish treatment with a removable orthodontic appliance, and the date of jaw impression and sex were listed on the dental cast. The dental cast used consisted of a pair of maxilla and mandibles intact or with no damage, no loss of anterior teeth, and no diastema or multiple diastema cases. From calculation of the minimum number of samples, 47 samples were collected from medical records and the study model storage room of the Department of Orthodontics Faculty of Dentistry, Universitas Indonesia.

The study was approved by the Ethics Commission. Research samples that met the inclusion/exclusion criteria were fixated. An interrater reliability test then was performed by the researchers and was remeasured by the experts. An intra-rater reliability test was conducted by the same researchers remeasuring at different times. Both tests were done on five samples ( $10 \%$ of the total sample) selected at random. The first and second measurements were then tested using the $\kappa$ test with expected inter- and intra-rater reliability values $>0.6$. Serial numbering of all samples and assessment of the malocclusion complexity with Little's Irregularity Index on the dental cast were performed before and after removable orthodontic appliance treatment. Little's Irregularity Index scores were then recorded in Microsoft Excel (Microsoft Corp., Redmond, WA, USA). The data obtained were processed and analysed using the SPSS program (SPSS, Inc., Chicago, IL, USA).

\section{RESULTS}

A total of 47 pairs of pre- and post-treatment dental casts were obtained from 40 female and seven male patients, regardless of completed or uncompleted treatment with the removable orthodontic appliance. Measurements were made over two weeks at the Dental Material Laboratory of FKG UI Salemba using Mitutoyo digital callipers with a precision of $0.01 \mathrm{~mm}$. Most patients $(14,29.8 \%)$ were 22 years old (average age 21 years), and most $(8,17 \%)$ had a treatment duration of 14 months (average duration, 17.19 months; Table 1 and 2).

An inter- and intra-reliability test was done twice to determine conformity of the measurement result using $\kappa$ calculation. The inter-reliability test was conducted between researchers and the expert, while the intra-reliability test was done between the researchers themselves with an interval of two days in $10 \%$ of patients (five samples). The lowest interrater reliability test value of 0.615 showed substantial agreement between the researcher and expert; hence, the measurement conducted by the researcher and the method used were considered reliable. The lowest intra-rater test result of 0.706 showed an almost perfect level of agreement; hence, the mea- 
surements made by the researcher were considered consistent.

Afterwards, the average alteration in average Little's Irregularity Index score on each jaw based on the grouping according to the measurement criteria was compared. Scores of 0, 1-3, 4-6, 7-9, and 10 indicated perfect alignment or no irregularities, minimum, moderate, severe, and very severe irregularities, respectively.

\section{DISCUSSION}

In this study, there were more female $(40,85 \%)$ than male $(7,15 \%)$ patients. Similar results also were found in the study by Bernas et al. [11] in Canada and in the study by Edman Tynelius et al. [9] in Sweden, in which women were more likely than men to receive orthodontic treatment with fixed and removable appliances. The tendency of women to pay more attention to facial aesthetic factors as compared to men was the possible cause of the higher number of female patients [11]. This is also a potential reason why women are more likely to seek removable orthodontic appliance treatment at our clinic.

The patients age in this study ranged from 12 to 24 years (average age, 21 years), with most $(14,29.8 \%)$ being 22 years old. Similar results were found in the study by Klages et al. [12] in Europe in patients who were undergoing fixed and removable orthodontic treatment, where the average age of the patients was 25 years or patients belonged to the group of late adolescents (age range, 21-30 years). Health and beauty are of great concern in this phase of life; hence, in late adolescence, a person tends to seek care that may improve their health and beauty, such as orthodontic treatment [12]. In contrast with the research conducted by Paula et al. [13] in patients who were undergoing fixed and removable orthodontic treatment, the average age of patients who received orthodontic treatment was 16 years (range, 1320 years), i.e. they were young adolescents. The young adolescent phase is a transition from physical and mental development to a new environment and a psychological structure of more mature nature, during which some aspects of facial appearance and dental aesthetics play in important role in self-confidence [13]. The different results in these studies may be due to the limited num-
TABLE 1. Distribution and frequency of the number of patients by age and sex in the Dental Hospital of the Faculty of Dentistry, Universitas Indonesia Integration Clinic in the years 2013-2017

\begin{tabular}{|l|c|c|c|}
\hline \multirow{2}{*}{ Age (years) } & \multicolumn{2}{c}{ Number of patients } & Total \\
\hline 12 & 1 & 0 & 1 \\
\hline 13 & 1 & 0 & 1 \\
\hline 15 & 2 & 0 & 2 \\
\hline 16 & 1 & 0 & 1 \\
\hline 17 & 2 & 0 & 2 \\
\hline 18 & 1 & 0 & 1 \\
\hline 19 & 2 & 0 & 2 \\
\hline 20 & 3 & 1 & 4 \\
\hline 21 & 3 & 1 & 4 \\
\hline 22 & 12 & 2 & 14 \\
\hline 23 & 4 & 0 & 8 \\
\hline 24 & 40 & 3 & 7 \\
\hline Total & & 7 & 47 \\
\hline
\end{tabular}

TABLE 2. Overview of the treatment duration on the patients at the Dental Hospital of the Faculty of Dentistry, Universitas Indonesia Integration Clinic in the years 2013-2017

\begin{tabular}{l|c|c|c|c|c|} 
& \multicolumn{2}{c}{$\begin{array}{c}\text { Minimum } \\
\text { value }\end{array}$} & $\begin{array}{c}\text { Maximum } \\
\text { value }\end{array}$ & $\begin{array}{c}\text { Average } \\
\text { value }\end{array}$ & \multicolumn{2}{c|}{ Mode } & SD \\
\hline $\begin{array}{l}\text { Treatment } \\
\text { duration }\end{array}$ & $\begin{array}{c}21 \\
\text { months }\end{array}$ & $\begin{array}{c}26 \\
\text { months }\end{array}$ & $\begin{array}{c}17.19 \\
\text { months }\end{array}$ & $\begin{array}{c}14 \\
\text { months }\end{array}$ & 3.99 \\
\hline
\end{tabular}

ber of study subjects and existing differences in the population, whereas in our study the age groupings used were according to the method of Newman et al. [14], i.e. young (12-18 years) and late (18-24 years) adolescence.

The duration in our study of treatment using a removable orthodontic appliance ranged from 12 to 26 months (average, 17.19 months), and most patients were treated for 14 months (17\%). This result differed from those of the study conducted by Al-Moghrabi et al. [15] on patients at some UK clinics, where the average duration of orthodontic treatment was 11.2 months. This

TABLE 3. Distribution of Little's Irregularity Index score on the patients at the Dental Hospital of the Faculty of Dentistry, Universitas Indonesia Integration Clinic in the years 2013-2017

\begin{tabular}{|c|c|c|c|c|c|}
\hline & $\begin{array}{l}\text { Minimum value } \\
(\mathrm{mm})\end{array}$ & $\begin{array}{l}\text { Maximum value } \\
(\mathrm{mm})\end{array}$ & $\begin{array}{l}\text { Mean value } \\
(\mathrm{mm})\end{array}$ & $\begin{array}{l}\text { Mode } \\
(\mathrm{mm})\end{array}$ & $\begin{array}{l}\text { Standard } \\
\text { deviation }\end{array}$ \\
\hline Maxilla before treatment & 0.63 & 8.31 & 3.48 & 4.13 & 1.98 \\
\hline Mandible before treatment & 0.97 & 7.38 & 3.29 & 2.92 & 1.49 \\
\hline Maxilla after treatment & 0 & 6.98 & 2.31 & 2.23 & 1.72 \\
\hline Mandible after treatment & 0 & 6.59 & 1.85 & 1.44 & 1.43 \\
\hline
\end{tabular}


TABLE 4. Comparison of the average score of Little's Irregularity Index on patient's maxillas after removable orthodontic appliance treatment at the Dental Hospital of the Faculty of Dentistry, Universitas Indonesia Integration Clinic in the years 2013-2017

\begin{tabular}{|c|c|c|c|c|}
\hline \multicolumn{2}{|c|}{ Before treatment (mm) } & \multicolumn{3}{|c|}{ After treatment (mm) } \\
\hline Information & Average & No irregularity & Minimum irregularity & Moderate irregularity \\
\hline Minimum irregularity & 2.25 & 0 & 1.92 & - \\
\hline Moderate irregularity & 5.24 & - & 2.80 & 4.92 \\
\hline Severe irregularity & 7.64 & - & 2.87 & 5.36 \\
\hline
\end{tabular}

TABLE 5. Comparison of the average score of Little's Irregularity Index on patient's mandibles after removable orthodontic appliance treatment at the Dental Hospital of the Faculty of Dentistry, Universitas Indonesia Integration Clinic in the years 2013-2017

\begin{tabular}{|c|c|c|c|c|}
\hline \multicolumn{2}{|c|}{ Before treatment (mm) } & \multicolumn{3}{|c|}{ After treatment (mm) } \\
\hline Information & Average & No irregularity & Minimum irregularity & Moderate irregularity \\
\hline Minimum irregularity & 2.6 & 0 & 1.46 & 4.35 \\
\hline Moderate irregularity & 4.97 & - & 2.19 & 4.59 \\
\hline Severe irregularity & 7.38 & - & - & 4.12 \\
\hline
\end{tabular}

TABLE 6. Changes in the number of patients based on Little's Irregularity Index score on patient's maxillas after removable orthodontic appliance treatment at the Dental Hospital of the Faculty of Dentistry, Universitas Indonesia Integration Clinic in the years 2013-2017

\begin{tabular}{|l|c|c|c|c|}
\hline \multicolumn{2}{c}{ Before treatment } & \multicolumn{4}{c}{ After treatment } \\
Information & Total & No irregularity & Minimum irregularity & Moderate irregularity \\
\hline Minimum irregularity & 30 & 8 & 22 & 0 \\
\hline Moderate irregularity & 14 & 0 & 9 & 5 \\
\hline Severe irregularity & 3 & 0 & 1 & 2 \\
\hline Total & 47 & 8 & 32 & 7 \\
\hline
\end{tabular}

TABLE 7. Changes in the number of patients based on Little's Irregularity Index score on patient's mandibles after removable orthodontic appliance treatment at the Dental Hospital of the Faculty of Dentistry, Universitas Indonesia Integration Clinic in the years 2013-2017

\begin{tabular}{|c|c|c|c|c|}
\hline \multicolumn{2}{|c|}{ Before treatment } & \multicolumn{3}{|c|}{ After treatment } \\
\hline Information & Total & No irregularity & Minimum irregularity & Moderate irregularity \\
\hline Minimum irregularity & 32 & 4 & 27 & 1 \\
\hline Moderate irregularity & 14 & 0 & 12 & 2 \\
\hline Severe irregularity & 1 & 0 & 0 & 1 \\
\hline Total & 47 & 4 & 39 & 4 \\
\hline
\end{tabular}

may be due to many other factors that influence treatment duration, such as severity of malocclusion, patient cooperation, operator skills, and sociodemography [6]. Our research was conducted at the Dental Hospital Faculty of Dentistry, Universitas Indonesia integration clinic between 2013 and 2017, where the operator was a dental student supervised by an orthodontist.
The initial anterior dental irregularity on the patient's dental cast before treatment with the removable orthodontic appliance was assessed using Little's Irregularity Index. There was a difference in measurements of the maxilla with the mandible cast, where the average maxillary anterior dental irregularity scores before and after treatment (3.48 and $2.31 \mathrm{~mm}$, respectively) with a removable or- 


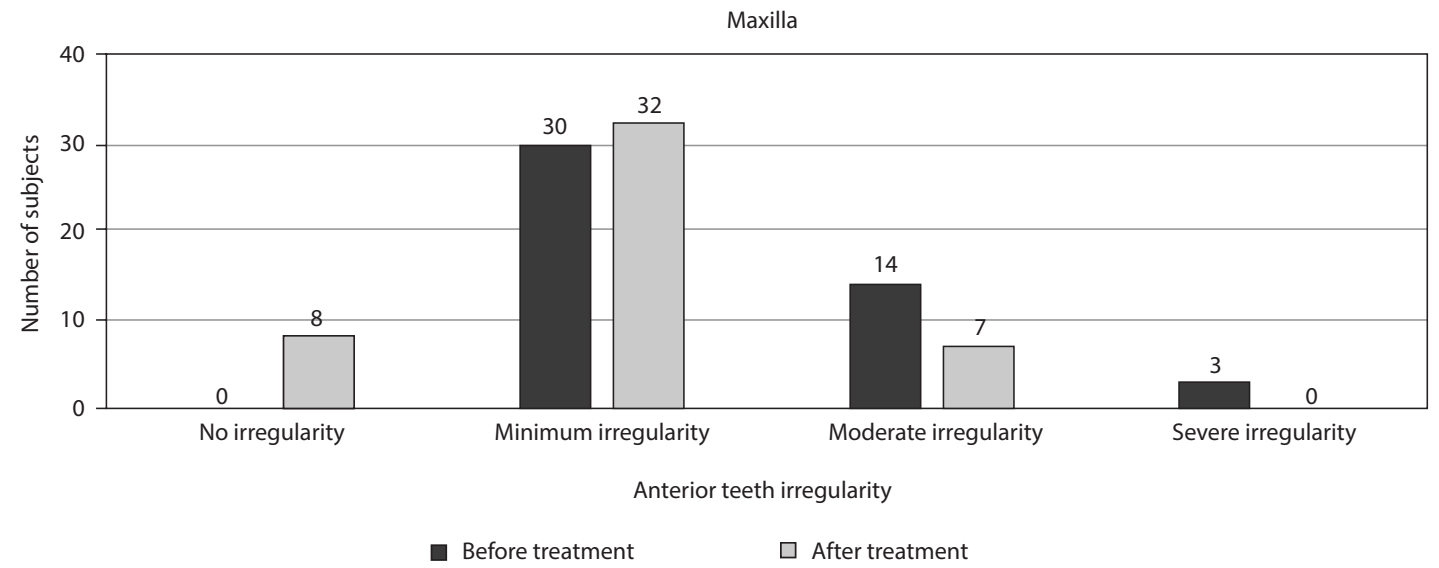

FIGURE 1. A comparison of number of patients based on the Little's Irregularity Index score on the maxilla before and after treatment with a removable orthodontic appliance at the Dental Hospital of the Faculty of Dentistry, Universitas Indonesia Integration Clinic in the years 2013-2017

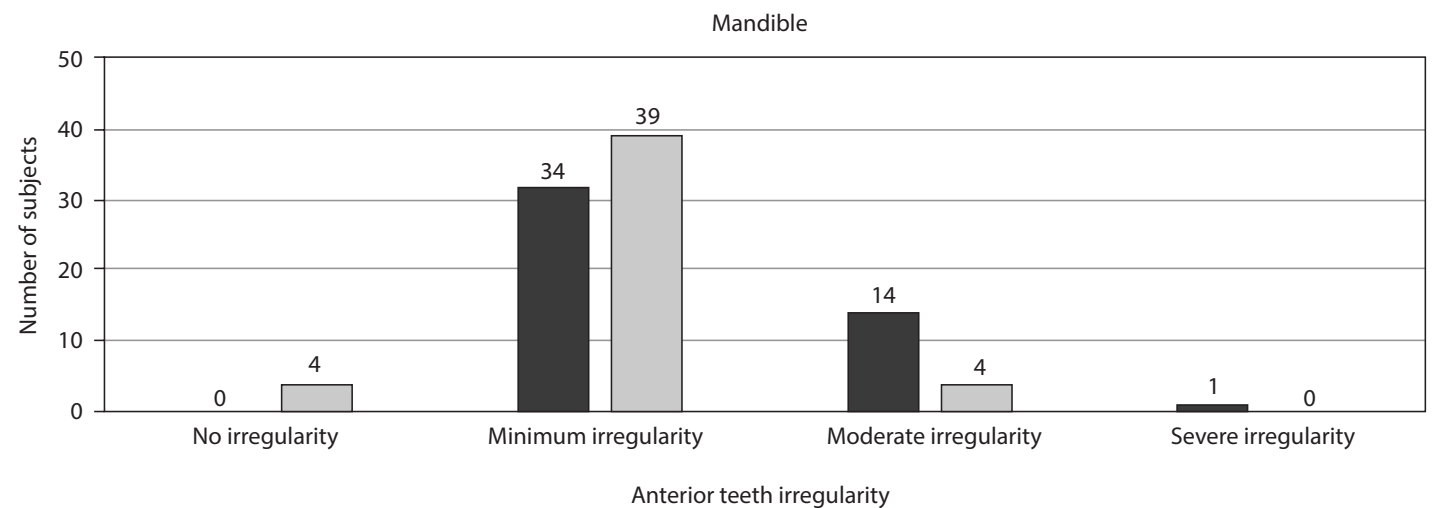

Before treatment $\quad \square$ After treatment

FIGURE 2. A comparison of the number of patients based on Little's Irregularity Index score on the mandible before and after treatment with a removable orthodontic appliance at the Dental Hospital of the Faculty of Dentistry, Universitas Indonesia Integration Clinic in the years 2013-2017

thodontic appliance were greater than those of the mandible (3.29 and $1.85 \mathrm{~mm}$, respectively). This result differed from that of the study result of Edman Tynelius et al. [9] in Sweden, who found a greater average Little's Irregularity Index score in the mandible as compared with that obtained from the maxilla (2.2 vs. $2.7 \mathrm{~mm}$, respectively). This may occur due to differences in the conditions in which the studies by Edman Tynelius et al. [9] were performed in patients with a relapsed tooth condition after removable orthodontic appliance treatment, where the maxilla had better relapse resistance than the mandible. In addition, it may also be due to the limited number of subjects and the methodology used in this study as compared with the study by Edman Tynelius et al. [9].

The score results were then grouped according to the measurement criteria $(0,1-3,4-6,7-9,10 \mathrm{~mm}$ indicating perfect alignment or no irregularities, and minimum, moderate, severe, and very severe irregularity). In this study, the results indicated that most patients with anterior dental irregularity who sought treatment at our clinic from 2013 to 2017 had minimal and moderate dental irregularities. These results are in accordance with the removable orthodontic appliance indication, which deals with cases that are not complex or that just involve a shift of the tooth location that requires only simple movements and does not involve skeletal abnormalities $[1,11]$. Similar results also were found by Bernas et al. [11] who in their study treated patients with a class I skeletal case with minimal and moderate irregularities. However, there were differences in the results of previous studies conducted by Hidayah in 2015, in which most patients had no or minimal irregularities [16]. The difference may be due to the limited number of research subjects and research methodology used in this study.

In our study, measurements were also made on the dental casts of the patients after treatment with a remov- 
able orthodontic appliance, to determine the anterior dental irregularity at the end of treatment, using Little's Irregularity Index. After treatment, the anterior maxillary and mandible teeth showed no, minimum, and moderate irregularities. These results indicated that patients had no or minimum anterior dental irregularities after treatment and suggested that the treatment provided at our integration clinic between 2013 and 2017 was in accordance with the function of the removable orthodontic appliance, which is to improve the condition of mild malocclusion without skeletal abnormalities $[1,5]$. The low number of patients who successfully achieved no irregularities or perfect alignment was probably due to lack of patient cooperation, such as with routine control and duration of appliance use $[1,5]$.

A detailed breakdown of the mean values and number of patients who had a condition alteration in the maxillary teeth after treatment with a removable orthodontic appliance was conducted to determine how much these values changed, and the number of patients undergoing group changes. In general, there were changes after treatment, which can be seen from the group changes that occurred. These results indicated that, in general, conditions improved after treatment, but only a few patients in the group with minimum irregularities before treatment experienced group changes. This might have been caused by the clinical difficulties in achieving no irregularities or perfect alignment conditions because the difficulties rely heavily on treatment plans and operator skills, as well as on patient cooperation [1, 6]. Treatment with a removable orthodontic appliance at our integration clinic was conducted by dental students who had never performed any orthodontic treatment in patients previously; therefore, the results may indicate that the treatment provided is good, since there was improvement in the mean value, although this was not followed by improvement of group alteration.

In the mandibles these results indicated that, in general, there was a change in the form of improved conditions after treatment, but some patients in the minimum irregularities group before treatment experienced changes in the moderate irregularities group. In line with a study conducted by Bernas et al. [11] in patients undergoing removable orthodontic appliance treatment, there were also subjects with worsening malocclusion due to poor patient cooperation, inefficiency, and appliance impairment. This was found more commonly in patients undergoing treatment with a removable compared to a fixed orthodontic appliance [11]. In addition, other factors existed, such as operator skill as well as sociodemographic characteristics. In this study, not all patients completed the treatment.

\section{CONCLUSIONS}

Our results suggest that most patients who sought removable orthodontic appliance treatment had minimum and moderate anterior dental irregularities in the upper and lower jaws. After treatment was complete, there was generally a decrease in the average Little's Irregularity Index or, in other words, improvement of the anterior maxillary and mandibular dental condition to there being no and minimal irregularities, and no patient had severe irregularities. Therefore, removable orthodontic appliance treatment provided by dental students at the Dental Hospital Faculty of Dentistry, Universitas Indonesia integration clinic between 2013 and 2017 can be considered appropriate treatment and in accordance with the indications and functioning of a removable orthodontic appliance.

\section{CONFLICT OF INTEREST}

The authors declare no potential conflicts of interest with respect to the research, authorship, and/or publication of this article.

\section{References}

1. Proffit WR, Fields HW, Sarver DM. Contemporary orthodontics. $5^{\text {th }}$ ed. Elsevier Mosby, Missouri 2007; 2-5, 347-350, 530-531.

2. Badan Penelitian dan Pengembangan Kesehatan. Departemen Kesehatan Republik Indonesia. Laporan hasil riset kesehatan dasar (riskesdas) nasional 2013. Jakarta, 2013.

3. Mitchell L. An introduction to orthodontics. $4^{\text {th }}$ ed. Oxford University Press, United Kingdom 2013; 2-6, 10-2, 15-6, 18, 102-105, 208-212.

4. Claudino D, Traebert J. Malocclusion, dental aesthetic self-perception and quality of life in a 18 to 21 year-old population: a cross section study. BMC Oral Health 2013; 13: 3.

5. Graber L, Vanarsdall R, Vig K. Orthodontics: current principles and techniques. $5^{\text {th }}$ ed. Elsevier Mosby, Philadelphia 2012; 4-5, 8-9, 22.

6. Skidmore KJ, Brook KJ, Thomson WM, Harding WJ. Factors influencing treatment time in orthodontic patients. Am J Orthod Dentofac Orthop 2006; 129: 230-238.

7. Little R. The Irregularity Index: A quantitative score of mandibular anterior alignment. Am J Orthod 1975; 68: 554-563.

8. Burns A, Dowling AH, Garvey TM, Fleming GJP. The reliability of Little's Irregularity Index for the upper dental arch using three dimensional (3D) digital models. J Dent 2014; 42: 1320-1326.

9. Edman Tynelius G, Petrén S, Bondemark L, Lilja-Karlander E. Five-year postretention outcomes of three retention methods a randomized controlled trial. Eur J Orthod 2015; 37: 345-353.

10. Guirro WJG, Freitas KMS, Janson G, et al. Maxillary anterior alignment stability in Class I and Class II malocclusions treated with or without extraction. Angle Orthod 2016; 86: 3-9.

11. Bernas AJ, Banting DW, Short LL. Effectiveness of phase I orthodontic treatment in an undergraduate teaching clinic. J Dent Educ 2007; 71: 1179-1186.

12. Klages U, Bruckner A, Guld Y, Zentner A. Dental esthetics, orthodontic treatment, and oral-health attitudes in young adults. Am J Orthod Dentofac Orthop 2005; 128: 442-449.

13. Paula DF, Silva ÉT, Campos ACV, et al. Effect of anterior teeth display during smiling on the self-perceived impacts of malocclusion in adolescents. Angle Orthod 2011; 81: 540-545.

14. Newman BM, Newman PR. Development Through Life: A Psychosocial. $13^{\text {th }}$ ed. Cengage Learning, Boston 2017; 60-62.

15. Al-Moghrabi D, Salazar FC, Pandis N, Fleming PS. Compliance with removable orthodontic appliances and adjuncts: A systematic review and meta-analysis. Am J Orthod Dentofac Orthop 2017; 152: 17-32.

16. Hidayah FN. Gambaran tingkat keparahan maloklusi, kelanjutan dan rutinitas perawatan pada pasien maloklusi kelas I dengan alat ortodonti lepas di RSGM-P FKG UI. Universitas Indonesia, 2015. 